Japanese Psychological Research

1962, Vol. 4, No. 3, 119-128

\title{
STUDY OF INTERESTS OF JAPANESE MEN WITH SPECIAL REFERENCE TO DEVELOPMENTAL ASPECT
}

\author{
HABUKU KODAMA
}

Japan Women's University

\section{Purpose and Procedure}

The purpose of the paper is to report briefly my studies about (1) how the interests of Japanese men change or develop from the time when they are in the middle school (lower high school) to the time when they get around 50 years old, settled in some occupation or other, through the high school (i.e., the senior high school) and the college years: (2) if and how the college students are differentiated in their interests from each other group, depending upon the major of the courses they are pursuing: (3) how the interests of the different groups of Japanese employed in different sorts of occupations are compared with those of the high school students (the senior high school).

The writer constructed a couple of years ago a vocational interest test for Japanese males, called the Strong-Kodama Vocational Interest Inventory, adapted from the Strong Vocational Interest Inventory. The Inventory contains ten scales for Japanese males, including journalist-radio-announcer, engineer, financiers I (including securities, insurance and trust firm executives), financiers II (bankers), business executives other than financiers, educators, government officials, natural scientists, and light industry mechanics and operatives. The scales have been standardized on the test results of nearly 2000 Japanese who were successfully engaged in ten different occupations, as contrasted with those of about 1000 high school students.

The Strong-Kodama Vocational Interest Inventory is composed of 7 parts with 360 items as follows:

\begin{tabular}{|c|c|c|c|c|}
\hline Part & I & Occupations & 100 & item \\
\hline Part & II & School Subjects & 40 & ני \\
\hline Part & III & Amusements & 60 & "צ' \\
\hline Part & IV & Activities & 45 & ", \\
\hline Part & $\mathrm{V}$ & Peculiarities of People & 60 & , \\
\hline Part & VI & $\begin{array}{l}\text { Comparison of Interest } \\
\text { between Two Items }\end{array}$ & 35 & ", \\
\hline \multirow[t]{2}{*}{ Part } & VII & Rating of Present Abilitie & & \\
\hline & & and Characteristics & 20 & s, \\
\hline
\end{tabular}

The studies reported in this paper embody, in part, the materials that accrued from the construction of the test, as well as the materials on the college students and others that were obtained especially for the purpose of the present study.

Change of Interests from the

Middle School to the High School

Years: A General Tendency

How do the interests change from the average middle school students to the average high school students? What are the characteristics of the change?

One of the ways to see how the change proceeds from the middle school to the high school period is to enumerate likes, dislikes and doubtfuls or indifferences of each subject on each item and sum them up separately for each group to which each subject belongs. The calculation was done by using the average reaction $\%$ of each group to each item.

The results show:

1. From the middle school to the high school period, there are, generally speaking, increases in likes and increases in dislikes, at the cost of doubtfuls or indifferences, which fact shows that the high school students give up doubtfulness and indeci- 
sion in their interests and become more definite in their attitudes than the middle school students.

2. There are more increases in likes than in dislikes shown in percentages as well as in the number of items in the choice of which the high school students become more definite. This indicates that the high school students come to assume, as compared with the middle school students, rather positive attitudes in more items than negative attitudes.

3. An exception to the rule is the high school students' reaction to the items on occupation, in which attitude they become rather negative in more items than do positive. In other words, the high school students become more definite in their choice of occupations by becoming more negative, compared with the middle school students.

4. During the period in question, it is remarkable that the "peculiarities of people" (Part V) registers, of the seven parts, the largest number in items of shifts to likes from doubtfuls and dislikes. The fact implies, I believe, that the high school students have become more comprehending of human nature and peculiarities, or more humanistic than the 8th graders.

5. The increases in likes for school subjects come next to those for human peculiarities.

To give a few examples, the average 8 th graders who were often adverse to funny humorous people give way to the 11 th graders who explicitly show liking for funny, humorous people. The 11 th graders also become somewhat tolerant of irreligious people, people who don't believe in evolution, people who chew gum, people who are blind, deaf-mute, etc.

One of the most important characteristics of the 8th and 11th graders is that regarding "the peculiarities of people" the 8 th graders have a far greater number of dislikes than likes, 9 items liked and 20 items disliked with 11 indifferent, while the 11 th graders have 14 dislikes. The shift of interest from the 8 th to the 11 th graders regarding human peculiarities implies that the 11 th graders have become more tolerant, that is, there is an increase in tolerance. A glance at the items in which the shift of interest takes place shows that the 11 th graders have become more humane, humanistic attitudes growing rapidly in the high school students, compared with the lower graders. The growing humanism appears in intellectual form as well as in affective form.

6. Reference has been made above to increases in likes and in dislikes on the whole, but in most cases the increases or decreases are not big enough to reverse the existing tendency. If, for instance, the likes $\%$ of an item have been larger than the dislikes $\%$ in the 8 th graders' responses, the situation, with the likes \% dominating, has not changed in the 11 th graders' responses, even though there have been increases in likes or dislikes. The increases or decreases have in most items served only to confirm or strengthen the existing tendency, only at the cost of indifferences decreasing.

It should be remembered in this connection, however, that the figures given here are the sum of the average likes $\%$ or the average dislikes $\%$ and are regarded as representing the general trend in their interests, regardless of individual items. They do not take into consideration the changes and differences in individual items, which will be done elsewhere.

7. In Activities (Part IV), the 8th graders show liking for "operating machinery", "saving money", "regular hours for work", "methodical work", " repairing a radio set or a clock", "cabinet making ", " care for animals", "raising flowers and vegetables", etc., but as they advance to be 11 th graders, the amount of liking gradually declines. On the other hand, the 8th graders are rather highly adverse to such activities as "interviewing clients", "making a speech", " engaging in arguments", but when they 
get to be 11 th graders, the dislikes decline in many cases.

\section{From the 11 th Graders to the College Juntors}

1. From the sum of likes and dislikes for the items, Parts I to $V$, including Occupations, School Subjects, Activities and Peculiarities of People, our youngsters become, generally speaking, increasingly positively-oriented, as they progress from the middle school to the high school and then to the college with the exception of medical students. It seems to be the trend in interests which is started in the middle school age and is followed up to the college years. That is to say, likes increase and dislikes decrease.
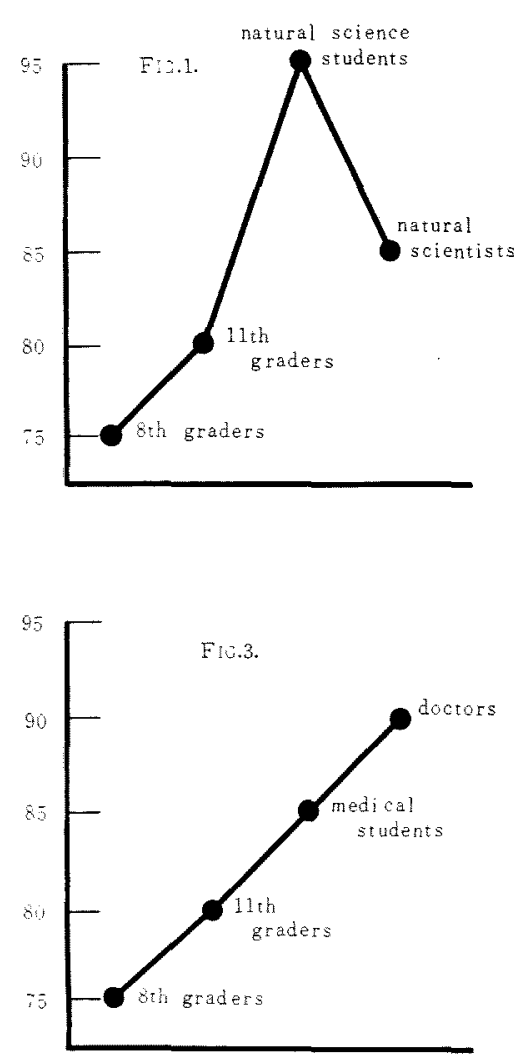

Change of interests, as indicated by sum of likes $\%$, according to different groups.
2. However, there are differences according to the major course the students are pursuing. The business students in the college are the most positively-oriented, and are followed, in order, by the engineering students, the natural science students and the medical students. From the similarity in trends, the business students and the engineering students form one group and the natural science students and the medical students another. The medical students are, generally speaking, more positive in their likes than the high school students, but the increase in likes is very slight while they show increases in dislikes in items, too, compared with the high school group.

3. The graphs $(1-8)$ give a rough idea
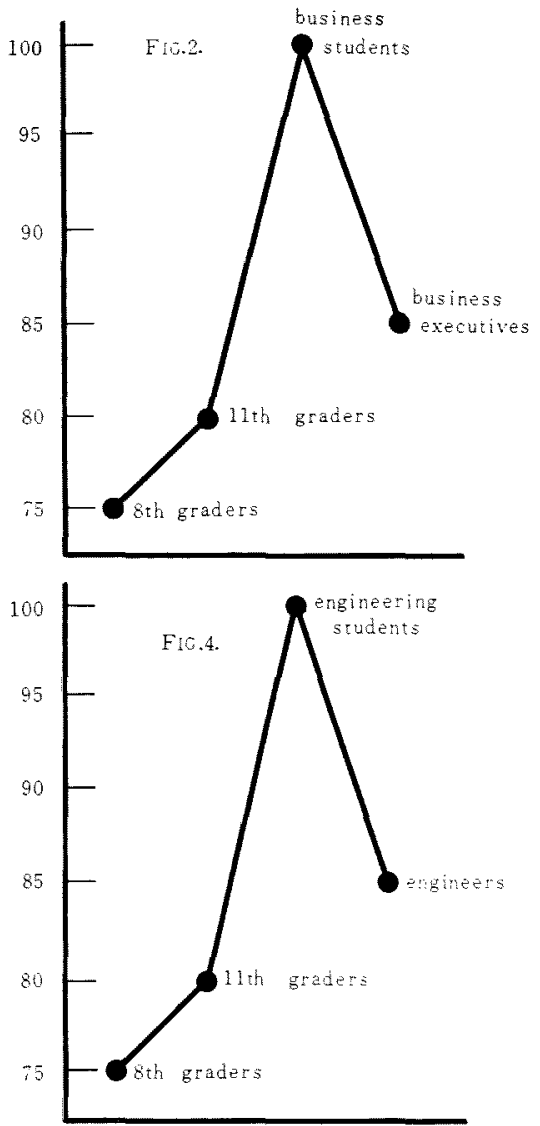
of the general trends in the change of interests from the 8 th graders to the 11 th graders, the college years and then to the four occupations most likely to correspond to each of the college groups. The figures represent the sum of likes $\%$ and dislikes $\%$ as calculated in the way described above. The graphs indicate that with the business students-business executives' group, the engineering group and the natural scientists group, the trend in increases in likes which started in the 8th graders and continued up to the college years begins thereafter to decline and drops down nearly to the level of the 11 th graders, while with the medical group, the increases which started in the middle school age continues to the medical college and then to the medical doctors.

Regarding the dislikes, as the graphs show, with the business group and the natural scientists group, the dislike decreases from the 8 th graders to the college years and then increases up to the level of the occupational groups, while with the remaining two groups, engineering and medical, decreases in dislikes which start in the middle school years continue to the 11 th grade and then, from the high school years on, remain unchanged throughout.

Regarding the trend in likes, as far as the figures of the graphs are concerned, there is not much difference among the four occupational groups, but with the dislike trend, there is a slight difference among the four groups.

In the four parts of Occupations (Part I), Amusements (Part III), Activites (Part IV), and Peculiarities of People (Part V), the trends in the shift of interests are practically the same as of the general trends above described, but the School Subjects (Part II) show a somewhat different trend in the shift as depicted in the graphs that follow.

From the graphs it can be said that likes in the school subjects increase in all the four groups until the college years, but after
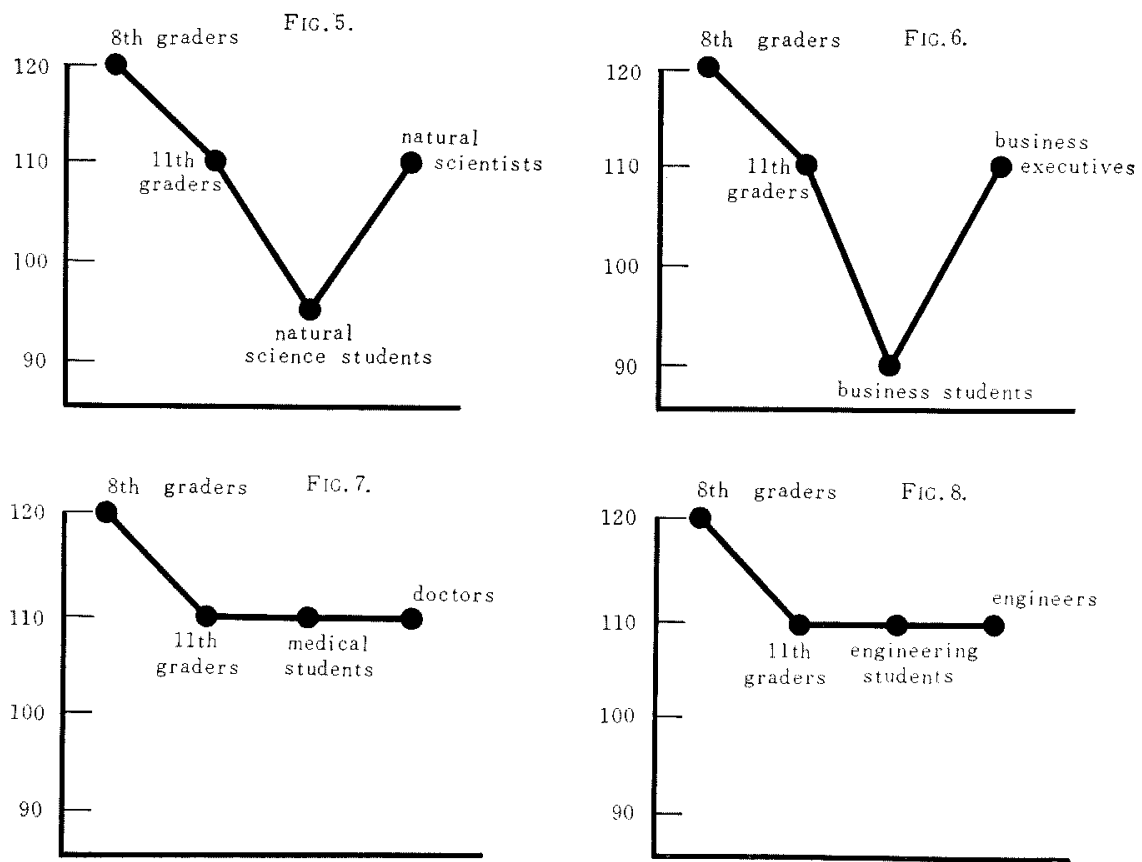

Change of interests, as indicated by sum of dislikes $\%$, according to different groups. unit $=100$ 
the college years, the business group and the engineer group show no more increase while the natural scientists group and the medical group continue a remarkable increase thereafter. Moreover, of the school subjects it may be said also that once a school subject is liked, it is most likely to remain so thereafter.

What has been attempted to do in this section is to show in rough outline how interests develop or change from the middle school years to the age of around fifty through the high school and the college years. It has thus been observed that the interests in the middle school years imply something still closed like the bud; in the high school years they begin to unfold in the way that has been suggested by the middle school students; in the college years the interests assumes a sudden remarkable development, like the flower coming to bloom; and around the age of fifty the interests have become constricted again to the level of the high school years.

\section{CoMparison betweEN INTERESTS OF 8TH GRADERS AND OF OCcupa- tional Criterion Groups}

How do the interests of high school students compare with those of occupational groups? Table 1 gives the correlation co-efficients between the mean interest scores of high school students and each of the ten occupational groups.

A couple of facts stand out from the figures. The group of business executives whose average age is 54.1 years, shows the greatest discrepancy from the group of high school students ( 16.5 years) with the least correlation score with the latter, while the light industry mechanics show the greatest correlation score with the high school group, about 15 years spanning the two groups. The discrepancy in interest between the groups is apparently a function of time.

However, time alone does not sufficiently explain the discrepancy in interests between the groups. The correlation of the
TABLE 1

Correlation coefficients between mean Interest Scores of high school students and each occupational group

\begin{tabular}{|c|c|c|}
\hline Occupational Group & Average Age & $r$ \\
\hline $\begin{array}{l}\text { Journalists-radio- } \\
\text { announcers }\end{array}$ & 47.8 yrs. & 0.88 \\
\hline Engineers & 49.6 & 0.81 \\
\hline $\begin{array}{l}\text { Insurance, Trust, } \\
\text { Securities }\end{array}$ & 48.6, & 0.81 \\
\hline Bankers & 49.4, & 0.82 \\
\hline Business Executives & $54.1 "$ & 0.70 \\
\hline Educators & 49.3, & 0.71 \\
\hline Gov't Officials & 47.2 & 0.75 \\
\hline Natural Scientists & $47.3 "$ & 0.77 \\
\hline Medical Doctors & 49.0, & 0.80 \\
\hline $\begin{array}{l}\text { Light Industry } \\
\text { Mechanics }\end{array}$ & $31.1 \%$ & 0.92 \\
\hline
\end{tabular}

high school group with the engineer group, whose average age is 49.9 years, is 0.81 , that with the journalist-radio-announcer (average age 47.8 years) 0.88 , that with the government officials (average age 47.2 years) 0.75 , and that with the natural scientists (average age 47.3 years) 0.77. The discrepancy in interests between the groups is also apparently a function of the occupation.

Comparison of the high school students' interests with those of the occupational groups will be made here according to the items.

1. Occupations

In 61 items of 100, no practical change has occurred in the choice of occupations on the part of the elders, which is not very different for different occupational groups.

The following occupational items which were not liked by the high school group have come to be liked by the occupational groups.

Biologist; school consultant and superintendent ; florist and orchardist ; critic (commentator); professor ; historian ; secondary school teacher; Japanese classical scholar; Shinto or Buddhist priest; artist. 
On the other hand, the following items come to be disliked:

Chauffeur; securities business; international trade; machinery operator and mechanics; journalist-radio-announcer (which, however, is liked by those engaged in the profession); banker (which, however, is liked by the bankers themselves); electrician and electrical engineer (which, however, is liked by the technician and the engineer) ; apothecary (which, however, is liked by the medical doctor).

There is much agreement among the different occupational groups about the likes and dislikes of these occupational items, implying some universality in interests among Japanese. About the shift of the interests in occupations, it may be said that (a) interest in educational work is for Japanese a late comer ; (b) interest in religion is late to appear for the majority of Japanese; (c) interest in artistic work and a job connected with nature begin to attract the majority late in life.

Among those occupations that come to dispel the old age are 3 ocupations connected with business, 2 with technical skill and journalism. It must be borne in mind that journalism and international trade attracted, of the 100 occupations, the largest number of youngsters as desirable occupations. As they advance in years, change in outlook on life has caused such a change in occupational choices.

2. School Subjects

Over 30 years' time since they left the high school has operated to implant more interest to the elders in the following school subjects.

Mathematics (with the exception of journalists); agriculture; composition; geography; history (with the exception of natural scientists); philosophy (with the exception of engineers); psychology; physiology (with the exception of journalists); ethics ; and education (with the exception of journalists).

The span of 30 years' time has apparently worked to implant in the elderly people increased interest in many school subjects, some of which, like agriculture and composition, were disliked by the high school youngsters. Regarding music, it may be said that the elderly people as tested for the study belonged to the generation who received no music education at all through their school years.

The above is the general trend, but with different occupational groups, there are differences in the shifts of interests.

Chemistry (interest increases with engineers but decreases in others); social studies $(-$ in engineers but + in all other groups); economics ( - in engineers but + in all others); sociology ( - in bankers and business executives but + in all others); science $(+$ in engineers, natural scientists and doctors, but - in all others); electricity (same as the preceding); medicine ( - in bankers, business executives and journalists but + in all others).

3. Amusements

The same trend runs in several different areas, it has been found, through the changes or shifts of interest from the high school students to the occupational groups. Changes of interest in amusements comprise the following types.

a. decline in interests associated with youthful romanticism or excitement, as jazz, card playing, etc.

b. decline in liking for amusements including physical exercises, like cycling, as well as decline in mechanical interests, as repairing radio set or clock, etc.

c. increases in liking for traditional or classical amusements, like flower arrangement, tea ceremony, etc.

d. increases in liking for reading.

4. Activities

Practically the same trend as referred to above rules in the shift of interest regarding Activities.

a. decreases in liking for mechanical operation or repair. 

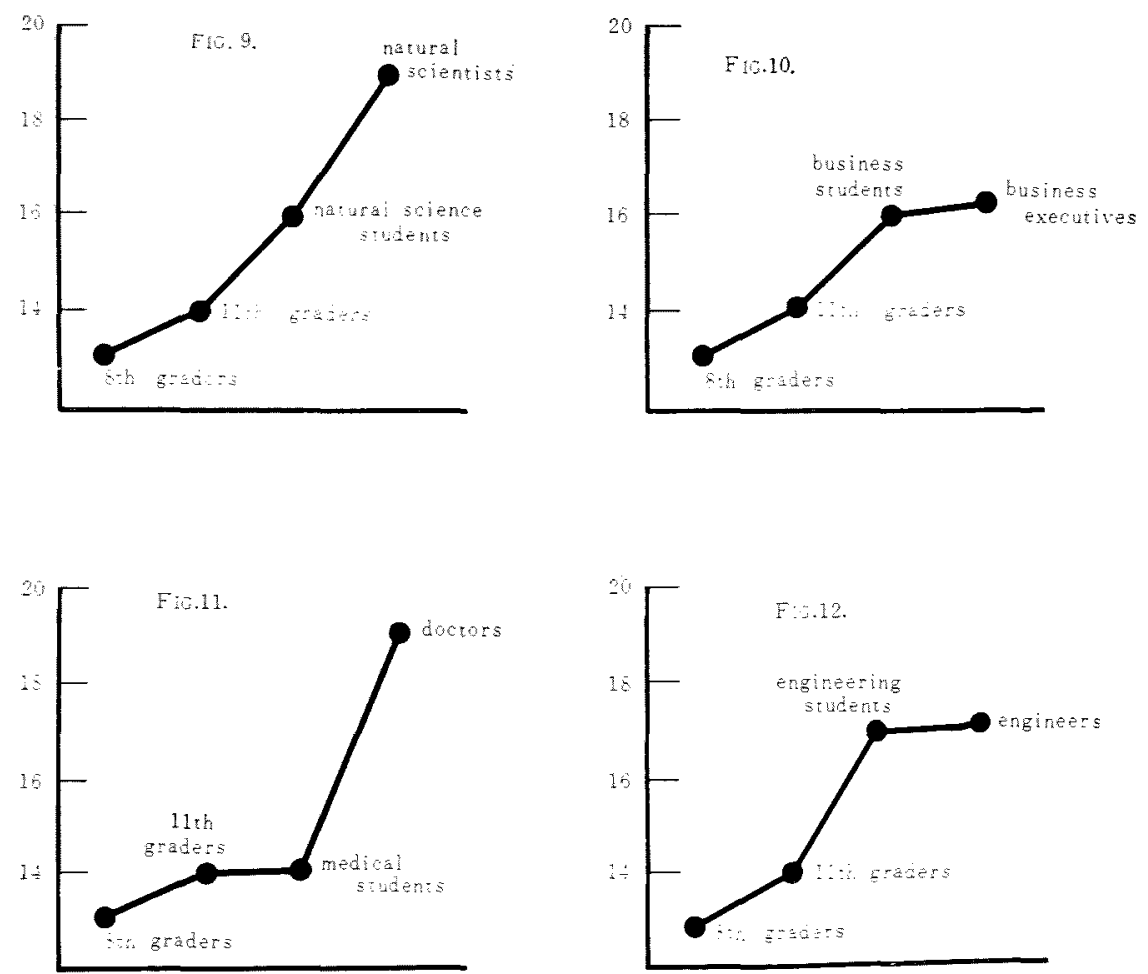

Preferences of school subjects: sum of likes $\%$, according to different groups. unit $=100$

b. increases in interest in educational or guidance activities.

c. increases in interest in activities including personal contact, as social activities and care for others.

d. increases in interests associated in Japan with the later years of life.

e. increases in liking for activities suggesting stability rather than adventure.

f. increases in confidence required in dealing with difficult problems.

5. Peculiarities of People

The trend that ruled in the shift of interest from the 8 th to the 11 th graders rules also in the shift from the 11 th graders to the accupatinal groups. The following items come to be liked more by the elderly people, as contrasted with the high school youngsters.

Religious people (with the exception of engineers); men who use perfume (with the exception of government officials and engineers); steady-going people (with the exception of journalists and engineers); tolerant people; intellectual people; people who assume leadership (with the exception of journalists and natural scientists).

With the following items, increases in dislikes appear:

cripples (with the exception of doctors); Bolshevists (with the exception of engineers); rough people (with the exception of engineers); loafers; emotional people; orphans; people who don't believe in evolution; carelessly dressed people; self-conscious people; blind people and deaf-mutes; mean, blunt, rude people; absent-minded people; people who borrow things; talkative people; pessimistic people; people who chew gum; spendthrifts (with the ex- 
ception of journalists).

There is also a slight decrease among journalists, natural scientists and doctors in liking for sportsmen; a slight decrease in liking, among journalists, engineers and natural scientists, for strong-willed people; an increase in dislike, among business executives, educators, engineers, natural scientists and doctors, for a level-headed person.

There are more increases in dislikes than likes, 17 items disliked to 6 items liked. The indefinite, indecisive attitudes shown by the high school students are replaced by more definite preferences of the occupational groups, who have become definite in 8 items by giving up indifferent attitudes, losing scarcely anything in the amount of liking.

Of the ten occupational groups, the natural scientists registers 27 dislikes among 60 items, the largest number of dislikes, against 13 likes, while the rest of the occupational groups range between 23 and 26 dislikes. Regarding likes, the light industry mechanics show 20 likes, the largest number of likes of all, and the rest of the occupations are distributed, in likes, excepting the youthful group of the mechanics, between 15 and 17 likes, with the high school students' 14. As the number of likes shown by the high school students is very close to those of the occupational groups with the light industry mechanics apart, so there is not much difference in items liked between the high school group and the occupational groups. Rather the differences come to the fore in connection with dislikes, the high school students' 17 standing against 23, the average number of dislikes of the occupational groups. The high school students do not much mind cripples, people with gold teeth, loafers, orphans, people who don't believe in evolution, carelessly dressed people, absentminded people, people who chew gum, spendthrifts, people who always agree with you, people who are obsessively exact and people who talk loudly, all of whom, however, are disliked by the occupational groups.

6. Comparison of Interests between Two Items

In the following items, the occupational groups show increases in preferences (as indicated by $t$ ) of the two items.

tdeal with people $v s$. deal with things.

The doctor is an exception, and also with the engineers and natural scientists, the increases scarcely reach $1 / 2$ of those of the other groups.

outside work vs. finside work.

The high school students give more preferences to outside work than to inside work.

treading a book vs. going to movies.

The high school group preferred movie going.

tdo a job yourself vs. delegate job to another.

fdefinite salary vs. commission on what is done.

playing baseball vs. fwatching baseball. The high school group prefer playing baseball.

twork involving few details vs. work involving many details.

taking a chance os. tplaying safe.

tsmall pay, large opportunities to learn vs. good pay, little opportunity to learn. work on a farm is. work in factory.

The high school students are in their preferences divided about equally between the two items, while the occupational groups, with the exception of light industry mechanics and engineers, choose working on a farm.

work in a factory $v s$. work as a sales clerk in a store.

The high school students choose factory work more than the other, along with business executives and educators.

The officials are equally divided between the two; financiers show a little more preference for sales clerk than to the other; engineers, light industry mechanics, natural scientists and doctors prefer factory work. The journalists, 
fleeing from both, remain indecisive.

7. Rating of Present Abilities and Characteristics

The responses of the high school students are characterized, as contrasted with the occupational groups, by lack of confidence. The occupational groups are all very confident, and rate themselves as being able to act in the desirable way in connection with the items with the exception of a couple of items. However, the high school students are not sure of themselves in twothirds of the items; the items of which they show a slight confidence in themselves are as follows.

Accept just criticism without getting sore ;

Keep silent in confidential affairs;

Can discriminate between more or less important matters ;

Can maintain my position in the face of superiors or friends;

Can plan my work in detail;

Can be steady in work;
Win friends easily.

\section{CoRrelations OF INTERESTS BETWEeN Different Occupations}

Space does not permit me to dwell fully on this subject, but I will present here Table 2 showing correlation coefficients of mean interest scores of different occupational groups, calculated on $\rho$ values of each item.

The following pair of occupational groups are arranged in the order of the values of co-efficients from higher to lower.

Bankers : trust-insurance-securities financiers $\quad .84$
Natural scientists: doctors $\quad .63$

Light industry mechanics : engineers

Natural scientists : engineers $\quad .39$

Gov't officials : journalistsradio-announcers

Natural scientists : light industry mechanics

Business executives : trust-in-

TABLE 2

Correlation coefficients between the mean Interest Scores of different occupational groups

\begin{tabular}{|c|c|c|c|c|c|c|c|c|c|c|}
\hline $\begin{array}{c}\text { Occupational } \\
\text { Group }\end{array}$ & 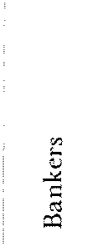 & 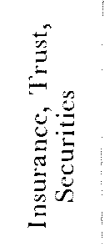 & 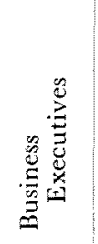 & 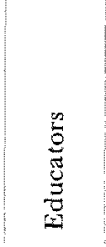 & 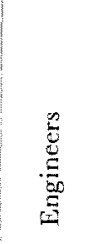 & 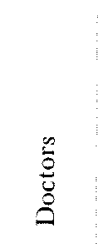 & 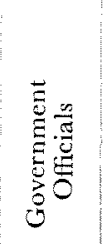 & 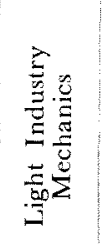 & 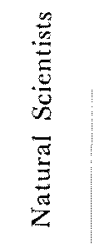 & 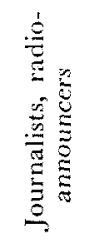 \\
\hline Bankers & $(.84)$ & .84 & .25 & -.05 & -.15 & -.31 & .26 & $(-.17)$ & -.32 & .18 \\
\hline $\begin{array}{l}\text { Insurance, Trust, } \\
\text { Securities }\end{array}$ & .84 & $(.84)$ & .27 & .03 & .03 & -.34 & .27 & $(-.22)$ & -.32 & .25 \\
\hline $\begin{array}{l}\text { Business } \\
\text { Executives }\end{array}$ & .25 & .27 & $(.27)$ & .02 & .02 & .26 & .06 & $(.06)$ & -.13 & -.03 \\
\hline Educators & -.05 & .03 & .02 & $(.24)$ & $(.24)$ & .17 & .24 & $(-.11)$ & .21 & .14 \\
\hline Engineers & $(-.15)$ & $(-.17)$ & $(.04)$ & $(-.01)$ & $(-.01)$ & $(.14)$ & $(-.24)$ & $(.40)$ & $(.39)$ & $(-.27)$ \\
\hline Doctors & -.31 & -.34 & .26 & .17 & .17 & $(.63)$ & .07 & .01 & .63 & -.06 \\
\hline Government Officials & .26 & .27 & .06 & .24 & .24 & .07 & $(.32)$ & -.09 & -.12 & .32 \\
\hline $\begin{array}{l}\text { Light Industry } \\
\text { Mechanics }\end{array}$ & -.17 & -.22 & .06 & -.11 & -.11 & .01 & -.09 & $(.40)$ & .29 & -.25 \\
\hline Natural Scientists & -.32 & -.32 & -.13 & .21 & .21 & .63 & -.12 & .29 & $(.63)$ & -.06 \\
\hline $\begin{array}{c}\text { Journalists, radio- } \\
\text { announcers }\end{array}$ & .18 & .25 & -.03 & .14 & .14 & -.06 & .32 & -.25 & -.06 & $(.32)$ \\
\hline
\end{tabular}


surance-securities financiers

Gov't officials : trust-insurancesecurities financiers

Business executives: doctors

Gov't officials : bankers

Business executives: bankers

Trust-insurance-securities financiers : journalists-radio-announcers

Gov't officials : educators

Gov't officials : engineers

The co-efficient value is highest between the bankers' group and the other kinds of financiers group, as might well be expected, followed by the natural scientists: doctors pair, the light industry mechanics: engineers, and so on. It was a surprise to find a rather low correlation co-efficients be- tween the business executives and the two groups of financiers.

The negative correlations are found between :

Doctors : trust-insurancesecurities financiers -.34

Natural scientists : trust-insurance-securities financiers -.32 Journalists-radio-announcers : light industry mechanics -.25

\section{ReFERENGES}

KodAMA, H. Strong-Kodama vocational interest inventory. Tokyo, 1960. (In Japanese)

Strong, E. K. Vocational interests of men and women. Stanford University Press, 1943.

(Received Aug. 7, 1962) 